\title{
SURVIVING COVID-19 AND BEYOND: A CONCEPTUAL FRAMEWORK FOR SMES IN CRISIS
}

\author{
Eyup KAHVECI $\mathbb{B}^{*}$ \\ SBS Swiss Business School, Zurich, Switzerland \\ Received 23 June 2020; accepted 13 January 2021
}

\begin{abstract}
This study sets out to review in detail the available information on SMEs crisis management. Despite SMEs' crucial role in the economy, relatively little research has been carried out on the effects of the economic crisis on SMEs and how they can cope with a crisis. This work will generate fresh insight into the crisis management for SMEs and provide a clear and easily understandable framework to survive COVID-19 and beyond. Ensuring sound cash flow during the crisis is the center of our framework. It is also crucial to have timely, accurate information and confident, courageous management. It will enable accurate analysis of the situation to restore or establish a new level of homeostasis from the perspective of bounded rationality. There is no generic treatment for overcoming a crisis. Tailor-made strategies and implementations empower companies to approach crisis resolution in the context of equifinality. There is only one goal: to survive the crisis. Yet, every company will have its own unique way to reach this goal.
\end{abstract}

Keywords: Coronavirus (COVID-19), Small and Medium Enterprises (SMEs), crisis management strategies, strategic decision making, enterprise survival.

JEL Classification: D21, D81, G01, L10, L21.

\section{Introduction}

Companies operate in a state of homeostasis and cannot survive long outside of it. A threat, large or small, to this state of balance requires prompt resolution and constitutes a crisis. It is natural for a crisis to cause negative feelings and be perceived as a threat. Depending on the level of severity, crisis can endanger or even obliterate some companies. Even in the best case, considerable organizational, structural, and operational reconfigurations (Kitching et al., 2009) might be required.

However, some studies emphasize that it can also be an opportunity, a source of innovation - and indeed, a chance for other companies to "prosper, because they understand how to exploit the fact that old patterns vanish and new ones emerge" (Marikova et al., 2016; Rumelt, 2009; Williamson \& Zeng, 2009). Every crisis exposes a rift in the underlying structure, generating potentialities in the business landscape. Companies that can recognize these niches and adjust to fill them will have competitive advantage during and after the crisis. In this paper, a discourse of measures and opportunities available under difficult and volatile economic conditions will be carried out specifically in terms of their significance for SMEs.
Small businesses comprise $99 \%$ of all businesses in US (Scarborough, 2014), Germany and Japan, 92\% in Turkey (Başçı \& Durucan, 2017), 98.5\% in Malaysia (Rani et al., 2019), and close to $90 \%$ in Baltic states (Eurostat, 2019). Moreover, they represent about $90 \%$ of businesses and more than $50 \%$ of employment worldwide (World Bank Group, 2017). SMEs and entrepreneurs play an important role in both developing (Rani et al., 2019), and developed countries' economies by contributing economic growth and wealth, creating employment, and enabling flexibility in production (Kahveci \& Wolfs, 2019; World Bank Group, 2017). A prosperous and dynamic small business sector is crucial to the overall performance of a domestic economy (Beaver \& Jennings, 2000).

The study of success factors for small businesses and entrepreneurs under normal economic conditions has received considerable attention (Beaver \& Jennings, 2000). However, far too little research has been carried out on how SMEs cope and, - just as importantly, - how they could cope with crisis, especially the one such as COVID-19 that is affecting the whole world today. The latest OECD (2020) report, acknowledges the tremendous global impact of the outbreak on SMEs:

*Corresponding author. E-mails: eyupkahveci@gmail.com; e.kahveci@faculty.sbs.edu 
"The current crisis (COVID-19) has affected SMEs disproportionately, and has revealed their vulnerability to the supply and demand shock (in particular with regard to their liquidity) with a serious risk that over $50 \%$ of SMEs will not survive the next few months". "A deterioration of the financial situation of SMEs could have systemic effects on the banking sector as a whole" (OECD, 2020).

In light of the gravity of the situation, it is vitally important to assess crisis mitigation measures available to Micro and SMEs (Tambunan, 2019). With respect to the complexity of crisis management, providing a conceptual framework for how to ride out COVID-19 will allow SMEs, entrepreneurs, private investors, finance organizations and government institutions to gain much-needed insight into the matter and to deal systematically with the crisis. It will also advance a more comprehensive grasp of the subject for researchers and professionals in the field (Nikolić et al., 2019). The main challenge faced by firms in crisis is acquiring a workable vantage point on their internal and external conditions, which would allow them to draw up a transformation roadmap and to link it with competitive advantages. It is hoped that the Strategic Crisis Management Framework proposed in this paper will provide SMEs with a clear and easily understandable algorithm to systematically cope with crises in general and COVID-19 in particular.

\section{Literature review}

\subsection{Defining crisis and factors affecting failure of SMEs}

The etymology of the word "crisis" as used to mean the turning point of a disease dates back to Hippocrates, and originates from the Greek krinein "to decide, judge" (Oxford Dictionary, 2020). In business literature, the term "crisis" describes a situation where any disruption of balance between internal business functions of a company and its external environment is regarded as a threat requiring decisive action to restore homeostasis.

Homeostasis (derived from Greek homoios, "similar" and stasis, "standing still", thus combining to mean "staying the same" in the context of biological systems) refers to the disposition of an organism to maintain an internal equilibrium in response to fluctuations in its environment. It means that for a business to continue functioning at an optimal level, it must use self-regulating control mechanisms to adapt to changes in its external conditions on the one hand, and to effect changes on its environment, on the other.

Causes of crisis can be either external environmental changes (market and economic conditions, political, technological, and sociological situations, terrorist attack, natural disasters etc.), and/or internal problems (mismanagement, internal conflicts, technical and production breakdown etc.). Every organization is vulnerable to crisis, - it can seriously disrupt business, significantly damage reputation, and/or negatively impact the bottom line.
Struggling to make urgent decisions while the company's existence is under threat is the very definition of crisis (Zuzák \& Rymešová, 2008). It is important to realize that, whatever the reason, most crises happen with little or no warning, are difficult to foresee and have a devastating impact on small businesses and big corporations (Thorgren \& Williams, 2020). As a result, uncertainty becomes the main reality (Balanovska et al., 2019).

Natural crisis is an unexpected type of crisis. A study done by Marikova et al. (2016) uncovers a $4.1 \%$ expectation of natural disasters among Czech SMEs. Another study by (Vojtko et al., 2019) indicates a 10.9\% occurrence rate for natural disasters. A common perception is that natural disasters in general and pandemics in particular are the types of events that are highly unlikely to occur.

A number of authors have studied factors affecting SME failure (Promsri, 2014; Theng \& Boon, 1996; White, 1974), concluding generally that firm failures might be prevented by more cautious management of financial assets and operational activities (Theng \& Boon, 1996). On the other hand, according to White (1974), out of many possible internal and external factors, inadequate education and training is the main reason for failure of SMEs. Promsri (2014) points out that if employees are educated properly, they are more likely to deal with a crisis successfully. In the same vein, he demonstrates that executives and more experienced staff have a higher level of preparedness for the crisis (Promsri, 2014).

In a study which set out to determine relevant managerial characteristics from crisis standpoint, Zuzák and Rymešová (2008) found that key competencies of the strongest performers are efficient resource mobilization, self-motivation and swift, creative and pragmatic decision making (Svoboda, 2009). It is also important to have flexibility in management and communication styles (Zuzák \& Rymešová, 2008). In another study conducted by Rani et al. (2019), winning qualities during crisis were shown to be "resourcefulness" (cash flow, investment, networking, assets, and adaptability) and optimism (preparedness to make decisions, take action, and sense of humor).

\subsection{Defining cash flow as lifeblood of the company}

SBS Swiss Business School Dean Dr. Wolfs expressed the very truth of COVID-19 as "I am not shocked in Switzerland by the high number of affected corona virus people, I am shocked with the number of SME's who complain after three weeks that they cannot survive due to a lack of savings or cash" (B. Wolfs, personal communication, April 1, 2020).

Campbell (2004) is no less emphatic in advocating cash flow management: "one of the most serious mistakes business owners make is trying to run their businesses without cash flow projections. This is like driving along on the freeway at 70 miles per hour with a blindfold on. It's not a question of whether you are headed for an accident. It's a question of how serious the accident will be and whether or not you will survive it." 
Even if a company has solid profit base and a strong balance sheet, it is still possible to go out of business due to lack of cash. For a given period of time, a company can have more revenue than its expenses, but if the in-flow of cash from sales does not match the timing of the firm's expenses it will be facing bankruptcy (Scarborough, 2014). Correspondingly, Chłodnicka and Zimon (2020) identify main reasons for SME bankruptcy in Poland as payment difficulties and cash flow problems caused by financial crises.

Both National Federation of Independent Businesses (NFIB) and American Express Open Small Business Monitor survey results reveal that cash flow management is one of the main problems encountered by small business owners (Scarborough, 2014). Udell (2001) study reveals that out of 2,200 small companies assessed, $68 \%$ have no cash-flow analysis at all. Just as disquieting is the fact that a "median small business has only a 27-day cash buffer" (Latkovic et al., 2020). Taken together, these studies support the argument that for a business cash flow is quintessential to staying alive. "Cash flow is the life force of your business. It fills the well. It powers the battery. It fuels the tank" (Grunden, 2015). Consequently, attending to the cash flow (before attempting to address other ailments) should be top priority of any company that wants to stay in operation.

\subsection{Crisis management strategies and methods}

In a comprehensive literature review, Kitching et al. (2009) identified pressures, threats and opportunities experienced by businesses during deep recession and coping strategies adopted by them. Three main categories outlined in the study are:

- retrenchment strategies - cost-cutting operations and harvesting non-core businesses,

- investment strategies - innovation and diversification,

- ambidextrous strategies - mixing retrenchment and investment.

Ultimately, SMEs are required to make strategic decisions about allocating resources to exploitation, exploration, or both. In previous studies, ambidexterity, - as defined by management efficiency and adaptability to environmental changes (Dolz et al., 2019), - was shown to increase manufacturing SMEs' survival odds in international economic crises. Dolz et al. (2019) demonstrate that SMEs employing ambidextrous strategies are proficient in transforming and reconfiguring themselves; likewise, their aptitude for quickly seizing opportunities and reassigning their scarce resources sustains their agility in contending with unpredictable circumstances.

Another research conducted by Türkcan and ErkuşÖztürk (2019) confirms that crisis survival rates are higher for small and younger firms.

According to the research conducted by Marikova et al. (2016), companies that have long-term goals and strategic management procedures in place have higher immunity against, are better prepared for, and better cope with crises (Marikova et al., 2016).

Using data supplied by commercial banks of 17 European countries, Andrieș et al. (2018) concludes that tight corporate governance procedures have a strong positive effect on banks' efficiency. This shows that although during a period of stability tight corporate governance structure is costly, it is helpful during a crisis since it provides more systematic and structural insight.

It has also been demonstrated that firms introducing any kind of innovation, especially process innovation, have higher probability of surviving the crisis than non-innovators (Cefis et al., 2020). Furthermore, firms who have longterm debt also have a higher chance to overcome the global crisis. Another study by Díaz et al. (2020) confirms earlier studies suggesting that innovation has a positive effect on employment even in a crisis period. A key research comparing ICT-intensive firms and less ICT-intensive ones (Bertschek et al., 2019) confirms that ICT-intensive firms coped better with the economic crisis of 2008-2009. In another research, Whittington (1991) identified best business strategies during recession as improving existing or introducing new products (Kitching et al., 2009).

In analyzing companies that overcame crisis Köksal and Özgül (2007) attributes their success to implementing both product development, and cost-saving strategies. While the former allowed firms to focus on niche markets, the latter resulted in improved technology and production methods. Similarly, Tambunan (2019) reviewed experience of several South East Asian MSMEs during $1997 / 1998$ and 2008/2009 crises and identified overseas and domestic market diversification as primary coping strategy. Next step was workforce adjustment by virtue of reducing working hours/days.

As demonstrated by Lydon et al. (2019), by using firm-level data from 20 European countries, firms are more likely to choose short time work (STW) as an option during the crises and it is an important mechanism for smoothing employment through shocks.

With respect to corporate crisis management, Mazaraki and Kasianova (2015) categorize activities in the context of proactive and reactive measures. Reactive crisis management is defined as planning and introduction of techniques for effective assessing, analyzing, managing, and resolving a crisis. The aim of reactive crisis management is to transform an unstable situation into pre-crisis conditions or to reach a new stable phase. On the other hand, proactive crisis management is a planned process aimed at averting a crisis before it happens.

"Pre-emptive action" (Kitching et al., 2009) and "timely reaction" (Svoboda, 2009) are conducive to SMEs' endurance for withstanding the crisis and emerging from it faster than competitors.

\subsection{Strategic crisis management tools}

In contrast to a wide academic coverage of abovementioned subjects, a relatively small body of literature 
concerns itself with crisis management tools. A paper by Mikušová and Horváthová (2019) uses a Mind Map format to outline a simple and understandable crisis management tool for SMEs. This approach was motivated by survey results (Mikušová \& Horváthová, 2019), namely, that most "SMEs lack the knowledge of how to initiate preparation for a crisis threat" and, consequently, are not prepared for it. Practicality of the framework was tested on several manufacturing SMEs.

Regarding crisis management strategies, Kryvovyazyuk (2013) maps experiences of Ukrainian industrial enterprises and concludes that under severe crisis conditions management is efficient in industrial-technological restructuring (3.6\%) and logistics management strategy (8.9\%). Conversely, under mild crisis conditions efficiency is higher in marketing strategy restructuring and penetration (16\%), market reengineering (28.5\%), regional expansion (17.8\%). The study indicates that most of the Ukrainian companies focus on marketing strategies to overcome the crisis (Kryvovyazyuk, 2013).

Similarly, Svoboda (2009) formulates crisis-related strategies based on their crisis matrix. The matrix has two axes: probability of crisis (from low to high) and its economic impact on the company (from low to significant level). If the impact is significant, independent of the degree of the crisis, resolute action is required, and the prime concern lies with alleviating financial setbacks caused by crisis. A prompt response to crisis calls for creative strategic decision-making that is supported by a reliable information system (Svoboda, 2009).

A good summary of a functional model has been provided in the work of Sylkin et al. (2019). "Ensuring the financial security of the enterprise" formed the focal point of their functional modeling during crisis. To achieve that, enterprise needs to:

- establish an information basis,

- determine internal and external threats to financial security of the firm,

- make appropriate decisions to tackle the crisis,

- implement decisions made.

Vojtko et al. (2019) compiled data from 183 Czech companies with 554 crisis scenarios to design a simulation system dynamics model. They followed this up with scenario analysis based on the most common crisis types and their combinations. Researchers suggest their method as a suitable strategic decision-making tool once it is tailored to specific firm.

Lastly, Zuzák and Rymešová (2008) delineate three pillars of crisis management strategy as: strong leadership, acquisition of necessary cash, and fundamental transformation of the company.

\section{Strategic crisis management framework}

\subsection{Methodology}

As mentioned in several research papers, SMEs frequently lack the knowledge (Mikušová \& Horváthová, 2019;
Theng \& Boon, 1996; White, 1974) of how to prevent a crisis or prepare for it. They usually do not have a crisis management system in place. Therefore, the principal objective of this paper is to outline a framework that will provide SMEs the means to analytically evaluate the situation and to maneuver through a crisis, in particular COVID-19 pandemic. The approach we have taken in our work is a mixed methodology based on a survey of over a hundred selected articles on the subject of crisis and strategic management and the work of Kahveci (2008) and McInerney and Barrows (2002). We are also inspired by mind mapping technique and system and casual analysis of Mikušová and Horváthová (2019) and functional modelling and graphical description of process methodology of Sylkin et al. (2019).

In this study we adopt the concept of enterprises as socio-economic living organisms, as used by Morgan (1997), Tomšík and Svoboda (2010). "Biological mechanisms seek a regularity of form", "while maintaining a continuous exchange with external environment." "Social systems also require such homeostatic control processes" (Morgan, 1997). Figure 1 illustrates healthy functioning of a company that has achieved such equilibrium between its internal and external environment; any fluctuation of this state requires recalibration.

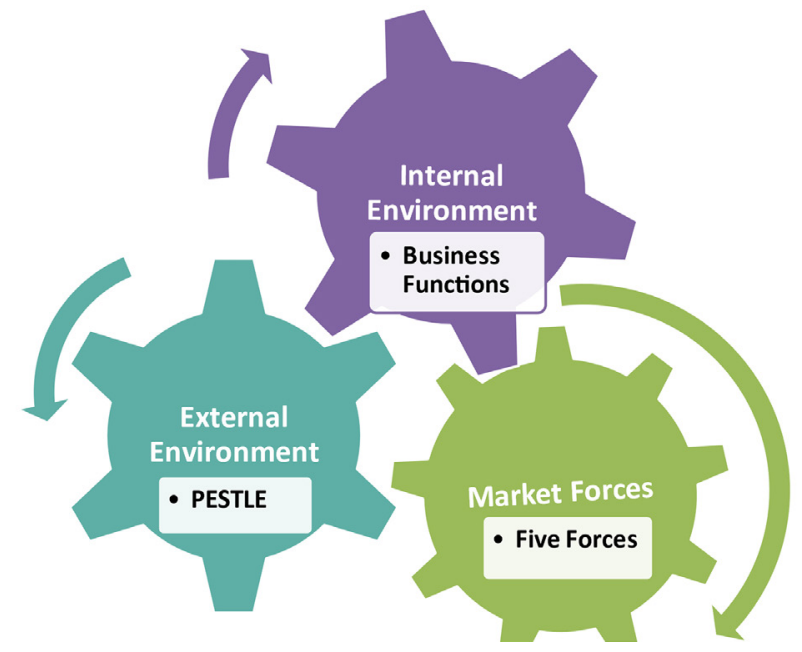

Figure 1. Homeostasis situation for a company

The dual challenge faced here by the firm's management is to strive for homeostasis while at the same time sustaining the long-term health of the company and keeping its immune system primed to ward off emerging threats. Strategic misalignment between a firm's resources, capabilities and external environmental conditions, such as the COVID-19 pandemic, will cause business failure (Amankwah-Amoah et al., 2020) unless necessary measures are taken. To avoid loss of performance and maintain productivity a company must adapt by aligning its goals, values, resources, and capabilities to fit its changing surroundings. This is accomplished by diligently screening internal and external environment and taking preventive measures to deflect detrimental effects forecasted by crises (Balanovska et al., 2019). 
Not unlike a biological organism, every firm operates within its unique structure, values, resources, and strategies and has unique tolerance ranges for every environmental factor. Contingency theory provides organizations with a useful paradigm for navigating the challenges of evolutionary adaptation. Barring that, natural selection of competitive market forces eliminates companies which do not satisfy new market requirements. Change is a constant, - a fundamental attribute of globalized environment. However, there are times of sudden and unexpected changes (crises) to be particularly conscious of and handle diligently.

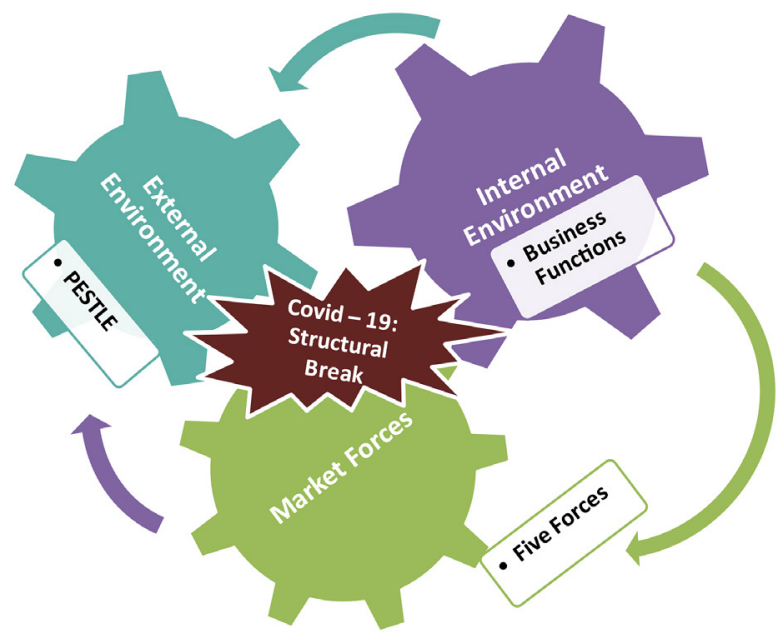

Figure 2. Structural Break caused by COVID-19

Typically, these rifts occur either in external or internal environment and constitute a disruption of homeostasis. In this case, the optimal function of a company is compromised until the problem is diagnosed and treated to full recovery (Figure 2). Depending on the root and the severity, the resolution of the issue might require unprecedented measures before the equilibrium is restored.

Even a cursory review of preliminary reports on the effects of COVID-19 reveals what could be interpreted as early signs of a "structural break" (Kitching et al., 2009; Rumelt, 2009), an event which results in huge financial, economic, and social consequences. Similarly, Thorgren and Williams (2020) refer to the pandemic as a "black swan" event, i.e. an event that "truly transcends business planning or resilience models".

Dramatic changes in underlying market structure and environmental conditions, uncertainties about competition, supply and demand, and financial situation are just some of the symptoms that would confirm the magnitude of changes brought on by such an event. A decrease in motivation and organizational performance (Buley et al., 2016), diminishing confidence and feelings of uncertainty, fear, and anxiety (AlKnawy, 2019) become a factor of everyday life. As a result, SMEs in OECD countries suffered major revenue loss and cash flow problems (Table 1), laying off employees and scrambling to restructure their business. The impact of COVID-19 has put these SMEs into survival mode, (Korankye, 2020), supporting the argument that the longer the duration of the crisis, the higher is the threat of going out of business or being taken over (Bartik et al., 2020).

Table 1. COVID-19 Impact on SMEs in OECD countries (source: OECD, 2020)

\begin{tabular}{|c|c|}
\hline Country & Impact on business \\
\hline $\begin{array}{l}\text { Asian } \\
\text { countries }\end{array}$ & $\begin{array}{l}30 \% \text { of SMEs expect to lay off } 50 \% \text { of their staff. } \\
50 \% \text { of SMEs have a month cash reserves or less }\end{array}$ \\
\hline Australia & $\begin{array}{l}41 \% \text { experience a drop in income of } 50 \% \text { or } \\
\text { more in the last two months }\end{array}$ \\
\hline Belgium & $75 \%$ report declines in turnover \\
\hline Belgium & $\begin{array}{l}\text { Over } 31 \% \text { of Belgium SMEs may not survive the } \\
\text { crisis }\end{array}$ \\
\hline Canada & $\begin{array}{l}50 \% \text { drop in sales, } 90 \% \text { of small business } \\
\text { affected, } 60 \% \text { experience significant impact }\end{array}$ \\
\hline $\begin{array}{l}\text { Canada } \\
\text { and the US }\end{array}$ & $90 \%$ of small business affected \\
\hline Finland & $\begin{array}{l}1 / 3 \text { anticipated a negative or very negative } \\
\text { impact }\end{array}$ \\
\hline Germany & $50 \%$ expect a negative impact \\
\hline Greece & $60 \%$ experience marked decline in sales \\
\hline Hungary & $60 \%$ expect a decline in sales \\
\hline Israel & $\begin{array}{l}55 \% \text { experienced no impact yet, } 1 / 3 \text { planning } \\
\text { layoffs }\end{array}$ \\
\hline Italy & $72 \%$ directly affected \\
\hline Japan & $\begin{array}{l}39 \% \text { report supply chain disruptions, } 26 \% \\
\text { decrease in orders and sales, } 92 \% \text { experience } \\
\text { economic impact }\end{array}$ \\
\hline Korea & $61 \%$ have been impacted \\
\hline Netherlands & $\begin{array}{l}50 \% \text { start-ups lost significant revenue, } 85 \% \text { of } \\
\text { SMEs in financial difficulty, } 20 \% \text { is at serious } \\
\text { risk }\end{array}$ \\
\hline Poland & $\begin{array}{l}1 / 3 \text { of SMEs experience increasing costs and } \\
\text { reduced sales } 27 \% \text { already encounter cash flow } \\
\text { problems }\end{array}$ \\
\hline UK & $\begin{array}{l}63 \% \text { see crisis as moderate to high/severe } \\
\text { threat to their business, } 69 \% \text { experience serious } \\
\text { cash flow problems, } 6 \% \text { out of cash, } 57 \% \text { three } \\
\text { months reserves or less }\end{array}$ \\
\hline USA & $\begin{array}{l}96 \% \text { experience the impact of the crisis, } 70 \% \\
\text { experience supply chain disruptions, } 50 \% \\
\text { negatively affected, } 75 \% \text { very concerned }\end{array}$ \\
\hline
\end{tabular}

The structural transformation necessitated by this extraordinary situation requires extraordinary management styles, radical measures, procedures, and decisions completely different from those employed under regular circumstances (Zuzák \& Rymešová, 2008). In this context, strategic management methods offer decision-makers "a discipline for thinking rigorously and systematically about uncertainty" (Grant, 2016), thus the more turbulent the environment, the more important it becomes to use these tools.

The research confirms that managers perform better when they apply strategic management frameworks and 


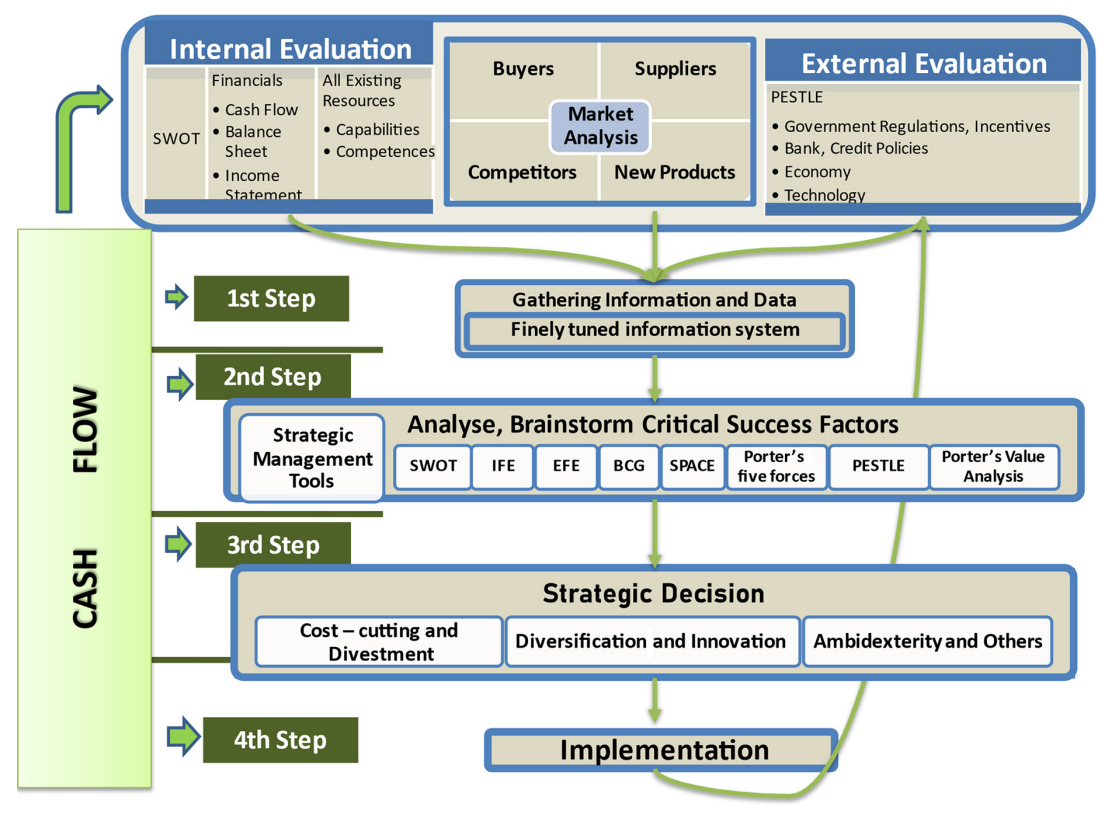

Figure 3. Strategic crisis management framework

strategic decision-making approaches (Kahveci, 2008; Marikova et al., 2016; Tomšík \& Svoboda, 2010). Strategic management model provides a dynamic and systematic method for matching organization's resources to opportunities arising within competitive environment. Thus, it empowers management to make rational, calculated decisions and facilitate coordination of functions and processes (AlKnawy, 2019; Grant, 2016).

Therefore, we formulate a Strategic Crisis Management Framework shown in Figure 3, to equip SMEs with information, tools, and procedures needed to tackle the crisis strategically.

\subsection{Preliminary requirement: cash flow}

As supported by categorical tone of our reviewed literature, the importance of cash flow management cannot be overemphasized. "Ensuring the financial security of the enterprise" (Sylkin et al., 2019) is therefore a focal point of our framework. Confident, decisive, and courageous management (AlKnawy, 2019) and solid cash flow are the two factors that are imperative for pulling a company through crisis.

As seen from Table 1, most countries report high percentages of SMEs with either financial operational problems or cash flow problems. Additionally, Table 2 shows that most SMEs do not have enough resources to survive longer than 3 months. In UK, Canada, and USA one third of SMEs expect to be out of business in a month, while Asian countries project an even more pessimistic estimate of less than a month for $50 \%$ of their SMEs. Furthermore, in a recent survey of over 1500 British SMEs, Cowling et al. (2020) found out that $8.6 \%$ small businesses do not have any cash at all. These companies must either significantly cut costs (if an increase in revenue is unlikely), take on more debt (if they are not over-leveraged), or declare bankruptcy (Bartik et al., 2020). International Finance Corporation (IFC) estimates 65 million firms or almost two fifths of MSMEs in developing countries to be facing a $58 \%$ lack of financing annually. On top of this $\$ 5.2$ trillion shortage already in effect pre-COVID-19, grim figures from abovementioned OECD surveys allow a first glimpse into just how detrimental the overall effect of the outbreak on this sector of economy could end up being.

Therefore, to prevent bankruptcy and improve company's prospects of surviving the pandemic, cash flow security must be an absolute guarantee. That is why governments are offering stimulus packages and central banks are making sure there is enough cash available to sustain businesses in operation. It is of crucial importance to make the most efficient use of available cash. This means

Table 2. COVID-19 Expectations of SMES in OECD (source: OECD, 2020)

\begin{tabular}{|c|c|}
\hline Country & Expectations \\
\hline $\begin{array}{l}\text { Asian } \\
\text { countries }\end{array}$ & $\begin{array}{l}50 \% \text { of SMEs have a month cash reserves or } \\
\text { less }\end{array}$ \\
\hline Belgium & $\begin{array}{l}50 \% \text { fear not to be able to pay costs in the short } \\
\text { term }\end{array}$ \\
\hline Canada & $1 / 3$ expect to be out of business in a month \\
\hline China & $\begin{array}{l}1 / 3 \text { out of business in } 1 \text { month, another } 1 / 3 \text { in } \\
\text { two months }\end{array}$ \\
\hline Korea & $\begin{array}{l}42 \% \text { fear being out of business in } 3 \text { months, } \\
70 \% \text { in six months }\end{array}$ \\
\hline Netherlands & $\begin{array}{l}50 \% \text { expects to be out of business within } 3 \\
\text { months }\end{array}$ \\
\hline UK & $1 / 3$ fear being out of business in 1 month \\
\hline USA & $\begin{array}{l}51 \% \text { indicate not be able to survive three } \\
\text { months, } 1 / 3 \text { lack the reserves to survive longer } \\
\text { than a few weeks }\end{array}$ \\
\hline
\end{tabular}


reaching out to the banks and suppliers about extensions on credit and accounts payable; at the same time, early payments on accounts receivables and efficient inventory management are imperative to expedite the in-flow and delay the out-flow, of cash.

Unburdening the cash flow also requires the choice of, for example, leasing and/or bartering over buying; instead of brand new tools and machinery, used ones; instead of selling on credit, considering cash-only and instead of paying cash, using any credit options. All these factors can positively impact company's cash flow.

Only after management ensures short-term financial security, it can move on to assessing other strategic options for company's long-term transitioning.

\subsection{First step: data-gathering}

Today's business environments are intensely competitive, thus for a company to operate effectively and efficiently, it is requisite to have a profound understanding of market conditions, external environment, and the business itself (Ansell \& Boin, 2019). Acquiring timely, accurate and high-quality information is therefore crucial (Svoboda, 2009). This will enable, in the steps to follow, to find appropriate treatment by means of a thorough analysis of the situation.

In order to identify the sources of competitive advantage, it is essential to be knowledgeable about the competitors, customers and vendors that constitute the playing field and the structure and systems the company is comprised of (Rani et al., 2019; Sylkin et al., 2019).

In terms of external environment, data can be obtained first-hand by observations and direct contact with customers (AlKnawy, 2019), competitors and industry experts, as well as second-hand from news and other published sources. Out of these, one especially relevant category is information released by governments on various assistance packages, ranging from deferral of tax, social security, debt, rent and utility payments, to loan guarantees, direct lending, grants, and subsidies. To examine this subject, Kaya and Balas (2019) carried out research with twenty-nine Eastern European and Central Asian countries' data and concluded that privately traded firms, firms with experienced managers, as well as sole proprietorship firms received more subsidies than publicly traded companies. These results are very encouraging, considering the fact that, for example, a European average for family-owned SMEs is $85 \%$ (Díaz et al., 2020). Government measures are indispensable for SMEs, due to their scarce resources, and should therefore be carefully monitored to filter out the most relevant ones.

Furthermore, collection and analysis of information about rival companies also contributes significant value in the form of competitive intelligence. Competitor analysis should not be ignored, as every action of competitors will have an influence on the firm.

In terms of appraising internal environment, it is imperative to understand the objectives of the business and values it upholds, the resources, capabilities, and competencies the company possesses, and how efficiently and effectively operational activities are executed.

Canvassing the opinions of all parties involved, holding daily and/or weekly meetings with key staff, can provide invaluable insight into the internal condition of the company and help stakeholders develop an in-depth understanding of actions required (Ansell \& Boin, 2019). Financial statements are another internal source of information that is too important to be ignored.

Companies which already have an efficient information system in place have a competitive advantage over the ones that have not. Every relevant piece of data might add critical value to the decision-making process and overall strategy making efforts.

\subsection{Second step: analyze with strategic management tools}

Every crisis is a test for companies and their management (Ansell \& Boin, 2019). A reality, in which it is necessary to compile critical details from all available sources, categorize them and formulate the best decision based on a few core principles (AlKnawy, 2019). The more uncertain and unprecedented the situation, the more challenging it is for companies to formulate strategies. Under these conditions, the spotlight is on managers to generate effective, legitimate and timely response, and to develop critical solutions (Ansell \& Boin, 2019) even if it might not be perceived as the best decision by other stakeholders (AlKnawy, 2019). This predicament epitomizes the notion of "bounded rationality" which refers to natural cognitive limitations - both in terms of available information and human information-processing capacity - that underlie rational decision making.

In the second step, data and information must be scrupulously analyzed by using all relevant strategic management decision making tools. As such, BCG model helps to understand the products' market position, and Porter's Value Chain is useful for recognizing opportunities for cost reduction and differentiation. In tandem with those, IFE (Internal Factor Evaluation Matrix), and SWOT analysis offer managers insight into company's objectives, values, resources, competencies, and business processes. The main target of this internal appraisal is integrating organizational capabilities and resources to maximize the firm's capacity to deliver on its value proposition, sharpening its competitive edge.

EFE (External Factor Evaluation) analysis matrix and PESTLE analysis (Kryvovyazyuk, 2013; Svoboda, 2009; Tomšík \& Svoboda, 2010) can be used to gain appreciation of how external environment will be changing in terms of political, environmental, social, technological, legal and economic factors. Other systematic tools such as Porter's five forces and SPACE (Strategic Position and ACtion Evaluation) matrix can be helpful in identifying the competition, industry's key success factors, interactions among firms and determinants of industry structure.

Therefore, without strategically analyzing and understanding the situation, it is difficult to make sound strategic decisions. 
Simulation analysis is one of the most useful tools to investigate alternative outcomes (Vojtko et al., 2019). The conditions for best, worst, and most likely scenarios should be delineated in detail so that revenues and expenditures can be precisely estimated. Besides other financial and non-financial forecasts, cash flow projections are the most valuable assets.

Equivalently, consulting outside expertise may supply actionable advice on how to keep the company in operation (AlKnawy, 2019; Ansell \& Boin, 2019). Instead of "consenting voices", successful leaders require "different perspectives” (AlKnawy, 2019).

\subsection{Third step: strategies}

In step three it is time to commit to a particular plan of action. Transformation is an unavoidable prerequisite to adaptation, and there are several competitive strategies to assist companies in this process. However, as advocated by Rumelt (2009), "a real strategy is neither a document nor a forecast but rather an overall approach based on a diagnosis of a challenge. The most important element of a strategy is a coherent viewpoint about the forces at work, not a plan." This coherent viewpoint is impossible to arrive at without first completing the work required in the previous two steps. Only after meticulous effort has been applied to data-gathering and analysis, can strategy formulation with specific methods be reliably attempted from the standpoint of bounded rationality.

\subsubsection{Cost-cutting and divestment}

Regarding business strategies to be chosen, cost-cutting strategies have been observed to be the most common approach adopted by businesses in response to crisis (Geroski \& Gregg, 1997; Kitching et al., 2009; Köksal \& Özgül, 2007). It is easier to decrease costs than to increase revenue. Hence, downsizing is the primary strategy for costcutting. Indeed, new data on COVID-19 by Shafi et al. (2020) has shown this to be a "knee-jerk" reaction by SMEs, as the immediate initiatives taken to overcome cash flow shortage were laying off employees, reducing staff salary and shutting down the business partially to reduce costs. Several countries have introduced policies related to shortening working hours, temporary layoff, and sick leave to help companies with their cost-cutting efforts. Some governments offer wage and income support for employees that are temporarily laid off, or for companies to secure employment (OECD, 2020). STW is an important mechanism for easing employment through shocks (Lydon et al., 2019). Other suggestions for remedial approach are reducing or suspending premiums, bonuses, compensation packages, work hours (daily or weekly) (Tambunan, 2019), and staff remuneration respectively, as well as making use of unpaid leave (Buley et al., 2016), or late salary payment (Gherman et al., 2015).

In terms of layoffs, retaining key employees is essential (Buley et al., 2016). Other alternatives to avoid costs associated with layoff are "employee-sharing" programs spontaneously or deliberately emerging in various contexts. Since cafes, hotels and restaurants are experiencing a collapse in demand, they can loan some of their labor force in partnership with delivery companies to accommodate grocery stores' spike in demand from quarantined online shoppers. Likewise, service industry can participate in "employee-sharing" programs or enlist their staff in fast-track training to qualify them for urgent relief vacancies in the healthcare industry.

Besides downsizing, there are many other strategies, that enable the company to lower its costs, - such as government subsidies, bank and debt financial restructuring, organizational restructuring, merger/acquisitions, alliances, business process restructuring ... etc. Any strategy will be on the table which can help company to lower any costs, such as rent, interest rate, wages, logistics, shipping ... etc.

Unmitigated divestment (Harrigan, 1980) is the least desirable option, but several possible scenarios may justify it, if:

- the company is financially unprepared,

- the firm is unable to generate necessary revenue,

- costs are climbing,

- competitive standing of the company is deteriorating.

The company can recoup asset value by focusing on core competencies and divesting products and operations in areas not related to it. Alternatively, if despite all effort to keep the company alive a viable survival strategy could not be developed, immediate liquidation can present a profitable opportunity to change the business model or industry and start over.

\subsubsection{Diversification and innovation}

Diversification is another competitive strategy to consider. Companies accomplish product diversification through investing and innovating and can show a lot of skill in diversifying their products and markets.

Diversification of markets (Kryvovyazyuk, 2013; Tambunan, 2019) can be achieved by mergers with other companies, acquisition of competitors, or formation of strategic alliances; for instance, grocery stores and restaurants entering into partnerships with delivery services to expand their offerings into larger territory. Another alternative of market diversification is migrating the whole business process into digital platform. For example, since working from home has become the new norm, IT companies have been investing more in the development of digital platform products, such as video conferencing software. It might be temporary just to provide enough cash flow during pandemic or it might become a new business standard post-COVID-19.

In a similar vein, diversification of products (Köksal \& Özgül, 2007; Whittington, 1991) can be accomplished by branching out and investing, - for example, into producing protective equipment and masks, as in the case of textile companies, or, in the case of consumer goods producers, modifying assembly lines to manufacture mechanical 
ventilators which are of critical importance in the fight against COVID-19. Chemical companies expanding their product lines into sanitizers and disinfectant materials is another example. Obviously, some businesses are better positioned for seizing specific opportunities of demand in the current pandemic. However, both in the less obvious and in all cases, identifying possible diversification paths requires SMEs to focus on core competencies and core values of the business. Successful diversifying not only bolsters the company's survival chances, but simultaneously renews its competitive advantage: failing to diversify, other players in the field will be thus coming nearer the risk of going out of business.

Evidence has shown innovations to be instrumental in achieving competitive advantage during and after the crisis (Cefis et al., 2020; Díaz et al., 2020; Flammer \& Ioannou, 2015). In 2008 global crisis, US businesses that carried through with R\&D and innovations spending, became more efficient, adapted easier to changing environment and enhanced their organizational structure (Flammer \& Ioannou, 2015; Roper \& Turner, 2020).

SMEs can employ a lot of creativity in coping with containment measures (OECD, 2020). All available alternatives considered, the most viable option for the future of the businesses is the one tailored to account for the firm's organizational capabilities and resources that are available to be rerouted in the direction of clearly identifiable trends. The company with right investment and winning product innovation will stand to gain a bigger market share in the post-pandemic economy.

\subsubsection{Ambidexterity/others}

The ambidextrous approach offers the most comprehensive strategy to gain competitive advantage, combining cost cutting strategies with effective diversification measures, such as incremental innovation adaptation (Dolz et al., 2019; Kitching et al., 2009). It links strategic flexibility and operational efficiency. It is, however, one of the most complex organizational challenges to undertake, since it puts under scrutiny managers' capacity to reconcile the dual effort of adapting to environmental changes by exploration of future opportunities while effectively executing daily business activities (Grant, 2016). Successfully balancing the two will not only help to cut the costs in the short term but will also enable firms to adapt to the future challenges by developing, innovating, and diversifying.

Other supplementary measures enacted alongside crisis management procedures might involve organizational restructuring, business process re-engineering, financial restructuring, industrial-technological restructuring, and marketing strategy restructuring (Kryvovyazyuk, 2013). However, as literature review shows us, strategies enabling "exploitation of existing resources to improve efficiency, with exploration of new sources of competitive advantage and innovation" (Kitching et al., 2009; Papadopoulos et al., 2020) are more likely to be successful during the crisis and beyond (Dolz et al., 2019).

\subsection{Fourth step: implementation}

Having understood the situation and formulated strategies to cope with crisis, the final step is to mobilize all resources to implement them. Implementation is more challenging than designing strategies (Hrebiniak, 2006). On the one hand, management is tasked with methodically executing strategies most fitting the active scenario; on the other hand, as pertinent details become newly available, it has to rigorously re-evaluate most relevant strategies and to enact necessary measures to benefit from new conditions. Situations of high level of uncertainty are transitional by nature and shift quickly to assume new (if also temporary) forms. Monitoring daily developments, such as government regulations, aid packages, policy announcements, is imperative for intake of strategically relevant information that can affect the market and the company itself. Like a doctor that pays daily visits to a critical patient to inspect their overall state of health for any improvements, the management is required to re-assess all four steps every day: what are the obstacles to successful execution? What problems must be confronted and overcome to make strategy work? Making systematically sound strategic decisions in volatile conditions is not straightforward, and critical analysis should revolve around clear market and economic trends insofar as they are possible to identify (Courtney et al., 2000), while keeping cash flow alive is an integral aspect of survival.

Adverse effects of crisis can be allayed by internally and externally communicating (AlKnawy, 2019; Buley et al., 2016) all of the facts about the threat and its consequences for the company. It is essential to be open and transparent with all stakeholders, to explain what is going on, what is the diagnosis and what is being done as treatment so far. These measures increase the level of organizational citizenship behavior and job satisfaction and enable employees to contribute more to company's survival (Psychogios et al., 2019).

\section{Discussion}

To summarize, COVID-19 is an entirely unexpected type of crisis with potentially devastating consequences for everyone affected. For businesses weathering the pandemic, the most pressing concern is surviving an event that has a magnitude of a structural break and is challenging all conventional business models. Companies face "mega uncertainty" (Kitching et al., 2009) concerning market structure, external, and internal environment of the company. Survival depends on both having healthy, sound immune system and performing timely, accurate diagnosis and treatment of the problem. In business context this means securing financial resources, the most important of which is cash flow, and devising and employing appropriate strategies for continued adaptation to the volatile conditions. To be able to do that, it is necessary to have an in-depth knowledge of the industry, market, and the company itself, as well as an integrated, comprehensive, and up-to-date 
information management system. If the management is not capable enough of understanding the situation and finding the diagnosis, outside consulting increases chances of survival (Thorgren \& Williams, 2020). Prescriptions are rarely meant to be palatable, but they are material to survival. Despite the crisis, positive thinking is key for creating a positive, rather than a negative, spiral (Meristö, 2020).

Even though there is no generic treatment for overcoming a crisis (Kitching et al., 2009), we can infer from the contingency theory, which provides perhaps the most appropriate frame of reference for this, that the best approach to coping with the crisis is dependent on both internal and external circumstances (Grant, 2016). In saying that no one crisis management procedure is universally applicable to all companies, we arrive at the concept of equifinality (or functional equivalence) as an external manifestation of the internal adaptive processes occurring within the contingency framework. The goal of survival is the same for all companies, but each company proceeds towards it from their respective starting points, and the prescribed methods to attain this goal are by necessity unique to each company. The individual successful solution is then a result of tailoring strategy and implementation to the particulars of the company, that is, to the resources, competencies, structure, and relations with external environment that are distinctively characteristic of it.

With respect to the relevance of these concepts to SMEs in crisis one of the most urgent and necessary directions for future research and resource allocation is to close the gap between theory and application. Overwhelmingly, business modelling is conducted in response to the needs of, and on the basis of data available on big corporations. To make these models useful to SMEs it is necessary to keep in mind the fundamental characteristic of SMEs (specifically, SMEs in crisis), that is - the lack of training and resources to invest into developing a crisis management tool. A survey conducted by Shafi et al. (2020) on the impact of COVID-19 on SMEs supports the stated characteristic, as $83 \%$ of survey participants report having neither any plan nor preparation to handle the current crisis.

However, as previously discussed, SMEs employing more articulate, well-developed strategies display more competency and dynamism in transforming and reconfiguring themselves (Dolz et al., 2019; Kahveci \& Wolfs, 2019). These companies are positioned to adapt their products, prices, and scarce resources more efficiently in response to crisis, and to quicker seize opportunities occurring in volatile conditions. Acting on this "strategic flexibility" positively affects their performance (Kahveci \& Taliyev, 2013; Kitching et al., 2009)

In our proposed framework, three main strategies that can be followed by SMEs are listed as follows:

1) Cost-cutting and divestment.

Fresh data from the frontlines of COVID-19 research by (Thorgren \& Williams, 2020) demonstrated that SMEs are reacting to this structural break by trying to cut costs and conserve resources. According to their findings, Swedish SMEs postponed investments, decreased general and labor-related expenses, and rearranged their contracts and terms. In practical terms, it is easier to decrease costs than to increase revenue. Several countries have introduced policies related to shortening working hours, temporary layoff, and sick leave to help companies with their cost-cutting efforts. Some governments offer wage and income support for employees that are temporarily laid off, or for companies to secure employment (OECD, 2020). However, as will be shown below, these measures alone are not enough to overcome the crisis and sustain long term competitiveness.

2) Diversification and Innovation.

An interesting finding by Thorgren and Williams (2020) is that in their efforts to cope with the pandemic, most SMEs have not been focusing on investment and innovation, because they are reluctant to follow any strategies that will augment their debt-to-equity ratio. This is where SMEs need help the most, because diversification and investing in innovation will provide sustainable solutions. These strategies create value by innovating products and services (i.e., offering a unique product and service or re-designing it), serving customer via new channels, and delivering a faster and superior customer service. The outcome is increased quality, flexibility, convenience, and performance (Scarborough, 2014).

In practical application, diversification and innovation should not necessarily be something too complicated and too expensive. From the perspective of SMEs, small changes count as diversification and innovation. Switching to producing protective equipment and masks, as in the case of textile companies, or, in the case of consumer goods producers, modifying assembly lines to manufacture mechanical ventilators, expanding product lines into sanitizers and disinfectant materials, using online distribution channels as is the case for food industry and offering take-away service are good examples of small and successful diversification and innovation strategies. Similarly, Thorgren and Williams (2020) are citing real-life examples of these small but crucial adaptations by SMEs. Therefore, targeted investment in innovation and R\&D support should be central to governments' responses to help SMEs. Another practical initiative is the funding allocated to help companies to upskill and reskill their workforce in response to the adverse conditions (Allas et al., 2020)

3) Ambidexterity /others.

To be able to sustain the business despite the challenges, it is vital for SMEs to follow diversification and innovation strategies in tandem with cost cutting strategies. As mentioned before, strategies enabling "exploitation of existing resources to improve efficiency, with exploration of new sources of competitive advantage and innovation" (Kitching et al., 2009; Papadopoulos et al., 
2020) are more likely to be successful during the crisis and beyond. As suggested by previous research, getting specific consultancy help from outside (AlKnawy, 2019; Ansell \& Boin, 2019; Thorgren \& Williams, 2020), even in the conditions of structural breaks, enables firms to accomplish innovative cost-cutting, diversification and employ ambidextrous strategies. Therefore, in terms of policy recommendations, it is imperative that governments act in accordance with this comprehensive understanding and provide the right incentives to help SMEs bypass the effects of COVID-19 to survive beyond it. Indeed, Thorgren and Williams (2020) confirm that under certain conditions, SMEs received up to $90 \%$ of costs for buying consultancy services for organisational and market development.

However, there is dire need for research and development of a usable methodology to implement theoretical frameworks into real life conditions, and for tailoring the available knowledge to the requirements of specific SMEs. In line with that, the policy decision-makers should continue to allocate funding on training and mentoring programs to crisis-proof the companies.

\section{Conclusions}

Early experience demonstrated that a pandemic such as COVID-19 requires an unprecedented mobilization of resources that both financial systems and the business world have found themselves unprepared for. The article adds value to the existing literature by offering a strategic framework specifically designed as a crisis response tool for SMEs based on the most current context. The principal limitation of this study was lack of broad coverage of datasets. On the other hand, one of the strengths of this study is that it integrates a wide selection of relevant research into a comprehensive strategic crisis management framework, emphasizing evidence-based methods and tools.

In terms of directions for future research, considerably more work will need to be done during and postCOVID-19 on SME experience comparing successful and unsuccessful use of coping strategies to identify which analytic tools are most useful and to investigate the degree of their efficacy. Case studies of individual companies would help to determine which tailored approach worked best under which conditions. In conjunction with the framework outlined here, it would provide a basis for detailed scenario analysis by policy makers and will be of invaluable help in developing training programs to educate SMEs on the benefits of strategic management tools, and to improve their crisis preparedness. We conclude in the hope of having contributed to the effort of bridging the gap between theoretical knowledge and practical applications, which requires advancing the awareness of the effective strategies available to SMEs to empower them to succeed under adverse conditions.

\section{References}

AlKnawy, B. (2019). Leadership in times of crisis. BMJ Leader, 3(1), 1-5. https://doi.org/10.1136/leader-2018-000100

Allas, T., Fairbairn, W., \& Foote, E. (2020). The economic case for reskilling in the UK: How employers can thrive by boosting workers' skills. McKinsey \& Company. https://www.mckinsey.com/business-functions/organization/our-insights/ the-economic-case-for-reskilling-in-the-uk-how-employerscan-thrive-by-boosting-workers-skills

Amankwah-Amoah, J., Khan, Z., \& Wood, G. (2020). COVID-19 and business failures: The paradoxes of experience, scale, and scope for theory and practice. European Management Journal (in press). https://doi.org/10.1016/j.emj.2020.09.002

Andrieș, A. M., Căpraru, B., \& Nistor, S. (2018). Corporate governance and efficiency in banking: evidence from emerging economies. Applied Economics, 50(34-35), 3812-3832.

https://doi.org/10.1080/00036846.2018.1436144

Ansell, C., \& Boin, A. (2019). Taming deep uncertainty: the potential of pragmatist principles for understanding and improving strategic crisis management. Administration \& Society, 51(7), 1079-1112. https://doi.org/10.1177/0095399717747655

Balanovska, T., Havrysh, O., \& Gogulya, O. (2019). Developing enterprise competitive advantage as a component of anti-crisis management. Entrepreneurship and Sustainability Issues, 7(1), 303-323. https://doi.org/10.9770/jesi.2019.7.1(23)

Bartik, A. W., Bertrand, M., Cullen, Z. B., Glaeser, E. L., Luca, M., \& Stanton, C. T. (2020). How are small businesses adjusting to COVID-19? Early evidence from a survey. Working paper 26989. https://doi.org/10.3386/w26989

Başçı, S., \& Durucan, A. (2017). A Review of Small and Medium Sized Enterprises (SMEs) in Turkey. Yildız Social Science Review, 3(1), 59-79.

Beaver, G., \& Jennings, P. (2000). Editorial overview: small business, entrepreneurship and enterprise development. Strategic Change, 9(7), 397-403. https://doi.org/10.1002/10991697(200011)9:7<397::AID-JSC519>3.0.CO;2-P

Bertschek, I., Polder, M., \& Schulte, P. (2019). ICT and resilience in times of crisis: evidence from cross-country micro moments data. Economics of Innovation and New Technology, 28(8), 759-774.

https://doi.org/10.1080/10438599.2018.1557417

Buley, N. V., Demchenko, T. S., Makushkin, S. A., Vinichenko, M. V., \& Melnichuk, A. V. (2016). Human resource management in the context of the global economic crisis. International Journal of Economics and Financial Issues, 6(8S), 160-165.

Campbell, P. (2004). Cash flow projections made easy. Inc.com. https://www.inc.com/resources/finance/articles/20041001/ cashprojection.html

Cefis, E., Bartoloni, E., \& Bonati, M. (2020). Show me how to live: firms' financial conditions and innovation during the crisis. Structural Change and Economic Dynamics, 52, 63-81. https://doi.org/10.1016/j.strueco.2019.10.001

Chłodnicka, H., \& Zimon, G. (2020). Bankruptcu risk assessment measures of Polish SMEs. WSEAS Transactions on Business and Economics, 17(3), 14-20. https://doi.org/10.37394/23207.2020.17.3

Courtney, H. G., Kirkland, J., \& Viguerie, P. (2000). Strategy under uncertainty. https://www.mckinsey.com/ /media/McKinsey/Featured\%20Insights/Managing\%20In\%20Uncertainty/ Strategy\%20under\%20uncertainty/Strategy\%20under\%20 uncertainty.ashx 
Cowling, M., Brown, R., \& Rocha, A. (2020). Did you save some cash for a rainy COVID-19 day? The crisis and SMEs. International Small Business Journal: Researching Entrepreneurship, 38(7), 593-604. https://doi.org/10.1177/0266242620945102

Díaz, G. A., Barge-Gil, A., \& Heijs, J. (2020). The effect of innovation on skilled and unskilled workers during bad times. Structural Change and Economic Dynamics, 52, 141158. https://doi.org/10.1016/j.strueco.2019.09.012

Dolz, C., Iborra, M., \& Safón, V. (2019). Improving the likelihood of SME survival during financial and economic crises: the importance of TMTs and family ownership for ambidexterity. BRQ Business Research Quarterly, 22(2), 119-136. https://doi.org/10.1016/j.brq.2018.09.004

Eurostat. (2019). Statistics on small and medium-sized enterprises - statistics explained. https://ec.europa.eu/eurostat/statistics-explained/index.php/Statistics_on_small_and_mediumsized_enterprises

Flammer, C., \& Ioannou, I. (2015). The dog that didn't bark: longterm strategies in times of recession. http://marriottschool.byu. edu/upload/event/event_368/_doc/flammer\%2010annou_recession\%201t\%20strategies.pdf

Geroski, P. A., \& Gregg, P. (1997). Coping with recession: UK company performance in adversity. Economic and social studies, Vol. 38. Cambridge University Press.

Gherman, R., Brad, I., \& Dincu, A. M. (2015). The effects of global economic crisis on human resources. Lucrări Științifice Management Agricol, 17(2), 64-67.

Grant, R. M. (2016). Contemporary strategy analysis: Text and cases. R. M. Grant (Ed.) (9h ed.). John Wiley \& Sons.

Grunden, J. (2015). The art of cash flow: tackling the lifeblood of your business. https://medium.com/@jodygrunden/ the-art-of-cash-flow-tackling-the-lifeblood-of-your-business-500543255972

Harrigan, K. R. (1980). Strategies for declining industries. Journal of Business Strategy, 1(2), 20-34.

https://doi.org/10.1108/eb038896

Hrebiniak, L. G. (2006). Obstacles to effective strategy implementation. Organizational Dynamics, 35(1), 12-31. https://doi.org/10.1016/j.orgdyn.2005.12.001

Kahveci, E. (2008). Strateji, Stratejik Yönetim ve Stratejik Yönetim Modeli. Verimlilik Dergisi, 2008(4), 7-30.

Kahveci, E., \& Taliyev, R. (2013). Export performance and industrial organization based strategy: an application on Turkish textiles firms by data envelopment analysis. European Journal of Economics, Finance and Administrative Sciences, 57(February), 69-81.

Kahveci, E., \& Wolfs, B. (2019). Family business, firm efficiency and corporate governance relation: the case of corporate governance index firms in Turkey. Academy of Strategic Management Journal, 18(1), 1-12.

Kaya, H. D., \& Balas, A. N. (2019). The global crisis and the subsidies to manufacturing firms. Studies in Business and Economics, 14(2), 41-54. https://doi.org/10.2478/sbe-2019-0024

Kitching, J., Blackburn, R., Smallbone, D., \& Dixon, S. (2009). Business strategies and performance during difficult economic conditions. For the Department of Business Innovation and Skills (BIS) (URN 09/1031).

http://eprints.kingston.ac.uk/5852/1/kitching-j-5852.pdf

Köksal, M., \& Özgül, E. (2007). The relationship between marketing strategies and performance in an economic crisis. Marketing Intelligence \& Planning, 25(4), 326-342. https://doi.org/10.1108/02634500710754574

Korankye, B. (2020). The impact of global Covid-19 pandemic on Small and Medium Enterprises in Ghana. International
Journal of Management, Accounting and Economics, 7(6), 320-341. http://www.ijmae.com/article_114337.html

Kryvovyazyuk, I. (2013). Innovative approach to strategy selection for enterprise crisis management. Economic Annals-XXI, 149, 77-84.

Latkovic, T., Pollack, L., \& VanLare, J. (2020). Winning the coronavirus war. McKinsey. https://www.mckinsey.com/industries/healthcare-systems-and-services/our-insights/winningthe-local-covid-19-war?cid=other-eml-cls-mip-mck\&hlkid= 7a8fe26b24454b52ad819ef6ac66b7d6\&hctky=\&hdpid=b07a2 abc-8303-49f3-a413-1fa7863ae720

Lydon, R., Mathä, T. Y., \& Millard, S. (2019). Short-time work in the great recession: firm-level evidence from 20 EU Countries. IZA Journal of Labor Policy, 8(1).

https://doi.org/10.1186/s40173-019-0107-2

Marikova, M., Rolínek, R., \& Vrchota, J. (2016). Crises and its occurence in SMEs in the Czech Republic. Journal of Logistics Management, 5(1), 1-5.

Mazaraki, A., \& Kasianova, A. (2015). Overview of proactive and reactive activities in corporate crisis management. Economics and Management of Enterprises, 3-4(1), 42-45.

McInerney, R., \& Barrows, D. (2002). Management tools for creating government responsiveness: the liquor control board of Ontario as a context for creating change. The Innovation Journal: The Public Sector Innovation Journal, 7(3), 1-24.

Meristö, T. (2020). Scenarios will help SMEs out of corona crisis and beyond. https://www.theseus.fi/handle/10024/342879

Mikušová, M., \& Horváthová, P. (2019). Prepared for a crisis? Basic elements of crisis management in an organisation. Economic Research-Ekonomska Istraživanja, 32(1), 1844-1868. https://doi.org/10.1080/1331677X.2019.1640625

Morgan, G. (1997). Images of organisation, international version (2nd Ed.). Sage.

Nikolić, N., Jovanović, I., Nikolić, D., Mihajlović, I., \& Schulte, P. (2019). Investigation of the factors influencing SME failure as a function of its prevention and fast recovery after failure. Entrepreneurship Research Journal, 9(3), 1-21.

https://doi.org/10.1515/erj-2017-0030

OECD. (2020). Coronavirus (COVID-19): SME Policy Responses OECD. https://read.oecd-ilibrary.org/view/?ref=119_119680di6h3qgi4x\&title=Covid-19_SME_Policy_Responses

Oxford Dictionary. (2020). Crisis | Definition of Crisis by Oxford Dictionary on Lexico.com also meaning of Crisis.

https://www.lexico.com/en/definition/crisis

Papadopoulos, T., Baltas, K. N., \& Balta, M. E. (2020). The use of digital technologies by small and medium enterprises during COVID-19: Implications for theory and practice. International Journal of Information Management, 55, 102192. https://doi.org/10.1016/j.ijinfomgt.2020.102192

Promsri, C. (2014). Thai employees' perception towards organizational crisis preparedness. Mediterranean Journal of Social Sciences, 5(14), 41-51. https://doi.org/10.5901/mjss.2014.v5n14p41

Psychogios, A., Nyfoudi, M., Theodorakopoulos, N., Szamosi, L. T., \& Prouska, R. (2019). Many Hands lighter work? Deciphering the relationship between adverse working conditions and organization citizenship behaviours in Small and Medium-sized Enterprises during a Severe Economic Crisis. British Journal of Management, 30(3), 519-537. https://doi.org/10.1111/1467-8551.12245

Rani, N. S. A., Krishnan, K. S., Suradi, Z., \& Juhdi, N. (2019). Identification of critical components of resilience during and after economic crises: the case of women food operators 
in Kuala Lumpur. Asian Academy of Management Journal, 24(Supp. 2), 111-126.

https://doi.org/10.21315/aamj2019.24.s2.8

Roper, S., \& Turner, J. (2020). R\&D and innovation after COVID-19: What can we expect? A review of prior research and data trends after the great financial crisis. International Small Business Journal: Researching Entrepreneurship, 38(6), 504-514. https://doi.org/10.1177/0266242620947946

Rumelt, R. P. (2009). Strategy in a "Structural Break". McKinsey Quarterly(1), 35-42.

Scarborough, N. M. (2014). Essentials of entrepreneurship and Small Business Management (7th ed., Global edition). Norman M. Scarborough (Ed.). Pearson.

Shafi, M., Liu, J., \& Ren, W. (2020). Impact of COVID-19 pandemic on micro, small, and medium-sized Enterprises operating in Pakistan. Research in Globalization, 2, 100018. https://doi.org/10.1016/j.resglo.2020.100018

Svoboda, E. (2009). New approaches to the solving of economic crisis in business management. Agricultural Economics (Zemědělská Ekonomika), 55(7), 307-313. https://doi.org/10.17221/50/2009-AGRICECON

Sylkin, O., Kryshtanovych, M., Zachepa, A., Bilous, S., \& Krasko, A. (2019). Modeling the process of applying anti-crisis management in the system of ensuring financial security of the enterprise. Business: Theory and Practice, 20, 446-455. https://doi.org/10.3846/btp.2019.41

Tambunan, T. T. H. (2019). The Impact of the economic crisis on Micro, Small, and Medium Enterprises and their crisis mitigation measures in Southeast Asia with reference to Indonesia. Asia \& the Pacific Policy Studies, 6(1), 19-39. https://doi.org/10.1002/app5.264

Theng, L. G., \& Boon, J. L. W. (1996). An exploratory study of factors affecting the failure of local small and medium enterprises. Asia Pacific Journal of Management, 13(2), 47-61. https://doi.org/10.1007/BF01733816

Thorgren, S., \& Williams, T. A. (2020). Staying alive during an unfolding crisis: How SMEs ward off impending disaster.
Journal of Business Venturing Insights, 14, e00187. https://doi.org/10.1016/j.jbvi.2020.e00187

Tomšík, P., \& Svoboda, E. (2010). Diagnostics and decisionmaking of the company management within the period of economic crisis and recession. Agricultural Economics (AGRICECON), 56(7), 303-309. https://doi.org/10.17221/53/2010-AGRICECON

Türkcan, K., \& Erkuş-Öztürk, H. (2019). Survival of firms in crisis: the case of Antalya Tourism City. Advances in Hospitality and Tourism Research (AHTR), 7(1), 1-23. https://doi.org/10.30519/ahtr.438189

Udell, G. (2001). Are you ready for the major leagues? Accounting/ Bookkeeping Article. Inc.com. https://www.inc.com/magazine/20010201/21842.html

Vojtko, V., Ladislav, R., \& Miroslav, P. (2019). System dynamics model of crises in Small and Medium Enterprises. Economic Research-Ekonomska Istraživanja, 32(1), 168-186. https://doi.org/10.1080/1331677X.2018.1552176

White, W. L. (1974). What's new in Washington. Journal of Small Business Management, 12(1), 32-35.

Whittington, R. (1991). Recession strategies and top management change. Journal of General Management, 16(3), 11-28. https://doi.org/10.1177/030630709101600302

Williamson, P. J., \& Zeng, M. (2009). Value-for-money strategies for recessionary times. Harvard Business Review, 87(3), 66-74.

World Bank Group. (2017). What's happening in the missing Middle? LESSONS from Financing SMEs. The World Bank. http:// documents.worldbank.org/curated/en/707491490878394680/ pdf/113906-WhatsHappeningintheMissingMiddleLessonsinSMEFinancing-29-3-2017-14-20-24.pdf

Zuzák, R., \& Rymešová, P. (2008). Managerial competencies in tackling an acute company crisis. Agricultural Economics (Zemédělská Ekonomika), 54(3), 125-128. https://doi.org/10.17221/240-AGRICECON 